\title{
ST(\&)S: Martyn Pickersgill Talks with Sheila Jasanoff
}

\author{
MARTYN PICKERSGILL \\ UNIVERSITY OF EDINBURGH \\ SHEILA JASANOFF \\ HARVARD UNIVERSITY
}

\begin{abstract}
In this interview, Sheila Jasanoff and Martyn Pickersgill discuss the contested meanings of STS, defined as either "science and technology studies" (often associated with European origins) or "science, technology, and society" (commonly seen as originating in the US). The interview describes how Jasanoff entered STS, and the ways in which she sought to bring together different traditions within the field. Jasanoff underscores how her intellectual and professional journeys were shaped through a mix of institutional context and personal choices, and reflects on the role she has played in shaping STS networks, programs, and departments. Jasanoff remains excited about the future of STS, yet also highlights the need for disciplining within the field. For her, STS represents a distinct mode of researching, approaching, and engaging with the world. This distinctiveness, Jasanoff argues, needs to be carefully cultivated and reproduced through creative but rigorous teaching and training. A reflection by Martyn Pickersgill follows the interview.
\end{abstract}

\section{Keywords}

science and technology studies; science, technology, and society; STS; disciplinarity

\section{"Science and Technology Studies" or "Science, Technology and Society"?}

MP My first question is, what is STS? In the UK we tend to say STS is Science and Technology Studies, but in the US there's Science, Technology and Society as well. What is it to you, that acronym? And what does that acronym really mean for you?

SJ I am in a somewhat unique position vis-à-vis that acronym because I came into the field through a program on Science, Technology and Society at Cornell, then I shepherded it into becoming a department of Science and Technology Studies. That may not be unique in itself, but when I came to Harvard and had to think about concocting a new STS program, because there wasn't one here, I had to reflect again on the name and chose Science,

\footnotetext{
'Martyn Pickersgill, Email: martyn.pickersgill@ed.ac.uk

2Sheila Jasanoff, Email: sjasan@fas.harvard.edu

Copyright (c) 2018 (Martyn Pickersgill, Sheila Jasanoff). Licensed under the Creative Commons Attribution Noncommercial No Derivatives (by-nc-nd). Available at estsjournal.org.
} 
Technology and Society, not Science and Technology Studies. For a long time I used to think, yes, of course names are important, but they're not over-important, and it's the practices that determine what you are really doing as a scholar. I still think that to some extent, but I have revised my views about the two STSs because I think that the two genealogies of STS are different, and taking that difference into account in a synthetic way creates the STS that I believe I stand for. So I want STS to be at one and the same time Science, Technology and Society and Science and Technology Studies. Science, Technology and Society came about in the US because of concerns that were coming out of society. Those concerns were fed in part by the anti-war movement of the 1960s, in part by environmental concerns, and in part by some of the big questions about technology and modernity. I have to say that US thinkers were not at the forefront in worrying about modernity as it relates to technological rationalism and all the things that German social theorists had been thinking about, and Foucault and French theory as well. American STS began instead with thinking about Rachel Carson and the environmental movement, and the military-industrial complex, and those kinds of issues, and also about identity politics, such as problems of race and gender in relation to science and technology. So the US played a major role in developing Science and Technology Studies in the directions of critical race theory, critical gender studies, and even critical legal studies, whereas on the European side the focal area of interest had much more to do with philosophical questions about what knowledge is and how it relates to materiality. Science and Technology Studies to some extent has taken science and technology as objects to look into in and of themselves, whereas Science, Technology and Society took science and technology as objects to study because of their interlinkages with the rest of the world. So, when I formed the STS department at Cornell, I tried very explicitly to draw these concerns together. Reaching out to Trevor Pinch was a unilateral decision--it was my choice pretty much, because STS there was nobody else there at the time to tell me what to do. That was part of an explicit attempt to bring the two sides of the Atlantic closer together. That we chose to name the Cornell department Science and Technology Studies had its own politics, which I'd be happy to tell you about, but to me it always meant bringing together two strands that I felt must be pursued simultaneously. These days I often say that STS is the field that reflects most profoundly on what it means for us to be scientific and technological civilizations, and that requires both thinking through where the specialness of science and technology lie, which is the Science and Technology Studies component, and what science and technology mean for the rest of the world, which is what the Science, Technology and Society part of STS has always covered. So for me it's not an "either/or," it's a "both/and," but I still think that putting society in there underlines what to me is the ultimate raison d'être of the field: it's not simply a re-description of science in our discipline's specialist language, it's also the vehicle through which we reflect on what it means to be rational societies, manufacturing societies, or inventive societies in particular ways. 
SJ That's a tortuous story. I was trained in historical linguistics at the PhD level, but so is my husband and we confronted the two-career problem, the fact that we were not going to get equally challenging jobs in an arcane field. My historical linguistics dissertation was on the morphological history of Bengali, which was not exactly the most popular language taught in American academia. So, after a good deal of anguishing, the very same year that I finished my PhD I also entered law school, pretty much with the idea that this was a trade and I would pursue it professionally. We were stuck in Cambridge because of Jay's job at the time, he was teaching at Harvard as a junior faculty member. The family position about my going to law school was: well, it can't hurt. But by the time I graduated, it was clear that I was not interested in corporate law and never was going to practice it. And through a stroke of good fortune a law professor of mine basically opened the door into a tiny environmental law firm and I started practicing environmental law in Boston. But then the academic job market hit us anyway. Because of Jay's job we had to go to Cornell, to upstate New York, Ithaca, a very small town, with no possibility of practicing environmental law.

In those days the practice-oriented people in Science, Technology and Society included people who were lawyers involved in environmental movements, and it turned out that one of the lawyers in my tiny firm-there were only three partners and me--knew Dorothy Nelkin because of her work on the anti-nuclear movement and other controversies. He gave me an introduction to her, and one of the things I did when I interviewed at Cornell in the spring of 1978 was go and talk to people in the STS Program. And they had a tiny amount of their original founding grant left to afford a half-time postdoc position for me. In the meantime, of course, I had to jump through hoops that I had never been trained for. I had to write a proposal for what I was going to do as a postdoc, and somebody I met here at Harvard suggested that I should propose to study the most recent of the major environmental laws that had been enacted, which was the Toxic Substances Control Act (TSCA). So I said for my project I'll look at the implementation of TSCA and it made sense given what I'd been doing as an environmental lawyer. Quite independently, three young men, all supported on soft money in the Cornell STS Program, had put together a proposal for NSF to look at the regulation of chemicals in Europe and the US. They had proposed France, Britain and the US as their comparison countries (two applicants were Americans and one of them knew French, the other was English). NSF sent the proposal back saying that they liked the idea of a comparative study but that this study needed legal expertise and it needed to include Germany and so they had to have somebody with German competence. So I, with a Harvard law degree and considerable amounts of German knowledge, was proposing to study chemicals, and these people were proposing to study chemicals with a mandate to bring in Germany and law. So the first thing that happened in my first year at Cornell was that I helped them re-write the proposal, and that essentially set me off on my entire subsequent career. 


\section{How Things Happen}

MP When you took over the department and you changed it from one STS to another STS, how common was that at the time?

SJ It was then and now absolutely sui generis. There's been nothing like that and I don't think there ever will be anything quite like that. I didn't "take over" a department at all. What happened after I'd been at Cornell for ten years was that I became director of the STS Program-I did assume the directorship, not take it over. But Cornell had done something very strange already vis-à-vis me before that happened. In 1987 they had given me tenure without the benefit of a department. They had discovered that they didn't need a department to grant tenure, which I think is unusual in the statutes of universities; I don't know, it may not be as unusual as it seemed then. But they concocted an ad hoc process and gave me tenure, so I was a tenured professor in the Faculty of Arts and Sciences, but not in a department. Then, a year later when they asked me to direct the program, the director position was endowed, and I asked if I could in effect hire somebody into the position that I was vacating when moving into the endowed position. So, within the next couple of years, through various ad hoc means whose details I don't think you'll want to know, we became a small faculty of something like three senior professors who did not have lines in any department and one junior professor who did not have a line in a department, plus affiliates of various sorts whom I was able to bring together, but they were not the core of the program. I have to stress it was still a program, not a department, and one of the distinguishing features is that programs typically do not have lines of their own. So we were an anomaly in being a program that did have lines of our own. Then NSF called me to say that they were announcing a competition for a major grant for graduate training in STS, and I was able to put together a faculty of about a dozen people and apply for that grant. Six months later NSF called me, or at least the person who was running the program called me, and said, "Sheila, the bad news is that you're not getting this grant but the good news is that I've persuaded the biological sciences division head"--it was under him that the grant competition was happening--"that they should award one more and we want you to reapply." So we reapplied and the whole process ended up taking a couple of years but we got the second one of those big grants, which was approximately a million dollars. It was big money then, it still would be fairly big money, and on the strength of that and partly to cure the anomaly, Cornell went forward with a discussion that had already begun about whether to take this strange appendix (the STS Program) in the Provost's office and convert it into a full-fledged department. That discussion took another year--so in '88 I became director of the Program on Science, Technology and Society, and in 1991 we got this NSF training grant and the College of Arts and Sciences voted to convert the program into a department. Then we were something like, as I recall, 14 FTEs (full time equivalents), of whom six had positions wholly in the new department. The others had joint appointments and together we represented as I recall something like eight separate fields. So the nomenclature was the least of it. How to weld this odd group of people together: one civil engineer, one economist, three philosophers, of whom two were moral 
philosophers and one was a philosopher of science, three or four historians, one biologist, one sociologist, and myself trained in law? How to take these people and build something that resembled a working intellectual faculty with some coherence-that was a far bigger challenge than deciding what to name the thing.

MP How important was work going on in Europe to you at that time? Was there quite a separation between the US tradition of ST\&S and what was largely but certainly not exclusively the European, particularly the UK, SSK kind of tradition?

SJ Obviously it was very important because one of the people who was totally instrumental in making these transitions happen with me was Trevor Pinch who came straight out of the UK SSK tradition. I had already been working with Trevor for more than a couple of years. I had been working with him since around 1990 because I invited him to join the editorial board for the first-I think-serious handbook of STS. It's often called the second, but in some ways the first was not a first for the whole field. Trevor was one of the coeditors along with me and two other editors from Michigan State University. So I was deeply committed from the start to building that bridge between the American and the European traditions. I was not very well informed about the different flavors of European STS at the time, and they hadn't sorted themselves out so clearly either. In those days Harry Collins and the Bath school, they were talking to Bruno Latour and they were talking to the SCOT people. There was much more of a sense of unified mission on the other side of the Atlantic, which has since fragmented into various different kinds of things. And SSK itself was more prominent in relation to other approaches. ANT hadn't reared its head as the great dominant STS formation on the other side of the Atlantic as yet. But, nevertheless, if you look at the 1995 STS Handbook's table of contents you will see that it's quite inclusive where the authors were coming from. It's very much not an American Handbook of Science, Technology and Society but a serious attempt to grapple with a whole international field. I don't remember who all the authors were at this point, there may be an over-representation in some sense of the Anglophone world. Brian Wynne wrote the chapter on public understanding of science, Steve Yearley wrote the chapter on environment, Malcolm Ashmore wrote one on new literary forms in STS, so there was quite a heavy sprinkling of people from the UK, and possibly a little less so of the total continental presence. But I genuinely think at that time the continental traditions had not crystallized to quite the same extent as they have since. It was meant to be the handbook of the field on both sides of the Atlantic. There's no question whatsoever that that was the intent.

\section{Disciplining STS}

MP When did STS become a field to you?

SJ There's some who would say it hasn't become a field yet, so when will it become a field is still the question for them. You know how genealogies are, you can point at the US Declaration of Independence and say that's when America came into being, but you might 
also say that it didn't really come into being until post-civil war reconstruction because most of the nation's citizens, a large group of its citizens, were not yet enfranchized, or not until still later when women got the vote. And when does the US become the US of the fifty states? So, on that analogy, I think a good field is always a field in the making, and I would sooner say it became a field in this broad period than at a particular date or a particular event. 1976 is the formation date for 4S (Society for Social Studies of Science). That's when people started getting a feeling that there is a thing here that is somehow separate from the other science and technology oriented professional societies, so it's an important date. Clearly the creation of STS programs has been rising in significance. At one time the Science Studies Unit was the only thing of its kind in Britain, but the Science Studies Unit has gone through various metamorphoses and you're celebrating your 50 anniversary in 2016, but not as the same thing. I would say that this century has seen a growth spurt. Another way to look at it is countries coming on board with STS societies of their own, and that has definitely been on the upswing in the last decade. I would say the initial formation in the 1970s, with developments like David Bloor and the Strong Program and the Science Studies Unit, was very important. By the way, the person at NSF who was so eager to fund these graduate training programs was very much looking to the Science Studies Unit as his model. That's a little detail that not many other people could supply you with. And there was a very specific idea of what retraining in STS would mean: it was about taking scientists and engineers and getting them to think about the social implications of science and technology, as opposed to today's full-blown version, holding that it doesn't matter what feeder field you come from, it's the topic that unites you. So the mid-70s was a sort of formation period, and the early 1990s as a peak of consolidation, and then the 2000s as a period of global diffusion. But global diffusion also means a kind of fragmentation because the initial question you asked--is it Society or is it Studies-has never gone away. And because certain frameworks are stronger now, like ANT, the dispersal of STS into other disciplines has had a reverse impact on what the field of STS actually is. So I think, ironically, more so than many other fields, we're victims of our own success, because lots and lots of people around the world today think they know what STS is, that is, they have some sense of what the abbreviation means, they even hire people with that training, but there hasn't been a comparable reflective synthesis, an ongoing synthesis within the field itself, about what we're supposed to mean to ourselves.

MP How important do you think it is to do that?

SJ I think it's terribly important if we want space in academia. People can disagree about this, certainly there are vehement voices in academia that say, just as at one point there was need for Women's Studies because women had been ignored, so at one time there was need for Science and Technology Studies because science and technology had been ignored. But today, look at any Anthropology department and they're doing anthropology of science and anthropology of medicine; look at many History departments and they're doing those same things historically; and look at philosophy, there's always been philosophy of science and philosophy of technology, but they're also taking new ideas on 
board, they're taking the new materiality on board, etc., so why do we need a designated thing called STS? You self-proclaimed STS-ers were a catalyst, and it was important and interesting when you did it, but now the disciplines are mature enough to be taking all this on board for themselves. I am a firm believer that this is not the case, but I'm not sure how many of my colleagues would put themselves on the line and agree with me in that respect. The reason I think that's not the case is multifold. One is that, experientially, you can show that people who are interested in knowledge and ideas, and for that matter in artifacts and materiality, in the classical disciplines tend to be marginalized and left to their own devices. Those are not the kinds of people that get hired when mainstream disciplines conduct their searches. You mentioned that you were going to Montreal. I was just there myself, but the Sociology Department at McGill is if anything diverging more and more from taking up sociology of knowledge as a central object of study, let alone something as specialized as sociology of medicine per se. So I don't think that the classical disciplines, which already have a focal thing that they think they study, are going to blend science and technology adequately into that focal subject. If you think that your subject is culture or chronology or social organization or financial exchanges and so on, then anthropology and history, sociology and economics, are not going to turn around suddenly and say we will put your topic-knowledge-at the center of our attention. So, if you think that science, technology, and knowledge are important enough for scholarly attention, where are you going to study those? Probably not in those older disciplinary structures. And related to that is a second consideration: STS is a field that has huge relevance for the cadres of people doing science and technology, and not just people studying it. We know that the Arts are to some extent in disarray, and most computer science students may not be interested in taking a course in the history of western civilization unless they're forced to. But they would take sociology of computer science or an STS course on the ethical, legal and social aspects of computer science, effectively delivered, if it enables them to understand some of their core preoccupations better. For instance, modeling: they may wish to understand some of the kinds of insights that STS scholars have come up with on the very idea of modeling. Many scientifically trained people eventually want to have careers not at the bench but out in the world, and for them again STS is a pragmatically more promising way of learning about the world they will encounter than trying to pick up dribs and drabs from an anthropology of culture course here, or a history of wars that did something with military technology there. And then, last but not least, I think over 30 years we have evolved our own methods and our own theoretical questions which are not the property of other fields. I've done more work elaborating the idea of coproduction than just about anyone else, and that word is now circulating fairly widely. People may misunderstand it or apply it in ways I would not, but nevertheless it's an example of a particular way of thinking about the world that came out of our desire to explain certain kinds of things. Similarly, I edited a book together with Sang-Hyun Kim on sociotechnical imaginaries and people are already using that concept quite widely. There's a little diagnostic. People in political theory came up with the idea of imaginaries, people in 
anthropology came up with the idea of imaginaries, but if you look at the classical texts in which imaginaries are discussed, these are projections of societies into futures with little or no place for science and technology. It's extraordinary: Benedict Anderson doesn't talk about science and technology, Charles Taylor doesn't talk about science and technology, Arjun Appadurai doesn't talk about science and technology. But how can modern societies have imaginaries about the future these days without science and technology? I think sociotechnical imaginaries will in fact take hold with a lot of people because they'll see instantly that, yes, there's some purchase to be gained through using this concept, but I wouldn't have thought of it in 1978 when I was transitioning from being a lawyer to being someone in a soft-money funded STS program. These are things that I've stumbled on, helped coalesce, found names for, developed in my own thinking and writing, and taught to others because I've been sitting together with other scholars who have these same interests in science and technology as objects of study. So I do recognize that in the passion and degree of my commitment to STS as a field of its own, I'm not alone. But I may be in a minority, maybe even in relation to the majority of my own field. However, that does not dilute my commitment and I really don't think that there's a different way to do the kind of critical reflection on society that I think is needed.

\section{Multiplying Questions and Connections}

MP Thinking about STS as a discipline, how would you like to see it evolve in the future?

SJ I think we have to pay lots more attention to training, and I think we have to train people to be intellectually generous and charitable. You may remember from your own time here my fondness for the term "epistemic charity." I think that STS scholars are suffering from the problem of inadequate specialization and hyper-specialization at one and the same time. I think that we have to take a position about our field that recognizes both the heterogeneity within it and the connections outside of it. Heterogeneity within means that you should not decide prematurely that STS is SSK or STS is SCOT or whatever, but you should recognize, as you would in a proper historiography course for instance, that there are many different ways to ask foundational questions about science and technology: what they are, how they sit next to each other, and so on. I don't think that people should be recognized today as STS scholars unless they understand something about the literature in our field, and the history of the field's development, which means good training to me. But at the same time I think that STS would be an impoverished field if we didn't acknowledge our connections to neighboring fields. Most STS scholars don't feel that they have things to say about neoliberalism or justice or equality, or most of those core normative questions about why winners should win and why losers should lose. Even when our community studies something like economics, we tend to get fixated on the instruments and not on the very existence of the market as a form of social organization and what that means for societies that depend on markets. So I would love to see an STS that is broadly cognizant of itself as a humanistic and social scientific field that respects its own traditions enough to 
offer people full-blooded introductions to our own genealogies. And then departments, if there were those, and programs, if there were those, might all still be inflected differently. There's nothing wrong in my mind with, say, Edinburgh emerging as the central place to study financial instruments because that's a specialty there, and people have developed it there, and some other place might be focusing on gender instead and yet some other place might be studying development. But there should be a commonality of training so that when people meet each other they recognize, even without the hand signal, that they belong to the same intellectual crowd. This is why I built the Science and Democracy Network (SDN). I say built, but that sounds far too intentional. I don't think it came about by intention in that sense. I started it in 2002 by inviting about three dozen friends and colleagues. Today the membership is something like ten times that many and it could grow to a thousand if we let it. The SDNers recognize each other, there's a mutual recognition that there are not just concepts we use in common, but also the kinds of questions that people ask. They see that there's an intellectual center of gravity, a place that people are pulled to. As you know all our meetings are plenary and people very happily sit through each other's talks and feel they can comment on any, and it's not topically defined and it's not defined by period. It's really defined by the kinds of questions that people are asking. I think that SDN should be one heavy strand in STS writ large. I don't have any desire to colonize the whole field, in fact my hope would be that STS would be vibrant in the way that big, inclusive fields are, like history. Our territory is the biggest there is, so there's no reason why we shouldn't have an equal richness of types of programs and specialties within. But there should be this sort of core, which by now I think includes, above all, the history of our own field and a respectful understanding of where its components come from and the strengths and weaknesses of those components - what kinds of critiques have been raised. People are forgetting for instance debates between Langdon Winner and SCOT, but those are part of our field. Today if we want to talk about something like trading stocks or climate modeling as a technology, we should still understand something about why people thought black boxes were important or not and why they opened them up or not. I would like to see STS go more in the direction of the disciplines but in the way that I think of disciplines, that they get their strength as much from internal conversations, not monolithic coherence, as they do from conversations outside, learning how other people are approaching our questions. To some extent "knowledge society" is a term sociologists use but they may not be querying knowledge in the same way that an STS scholar would.

MP You mentioned as well about the distinctiveness of STS methods, and that's often a debate, certainly in the UK, about "what is an STS method?" So, what is an STS method?!

SJ Couldn't any social science ask that question? First of all, there are debates about quantitative versus qualitative methods in our field, as in any others, and there are debates about interpretive versus empirical methods in our field as much as in any others. I do think there are by now some core STS methods. Both lab studies and controversy studies are particular things that we do in particular ways. The idea of the controversy as entailing 
methodological relativism or methodological agnosticism is I think ours, and to that degree the strong program survives. I think ideas of symmetry and reflexivity, which are part of our meta-theoretical repertoire, or rather meta-methodological repertoire, those are particular to us. I think coproduction offers a number of, not methods per se, but methodological entry points about when we look and what kinds of things we look at, and I think it goes beyond controversy studies. So I say in the coproduction chapter in States of Knowledge that one should look at moments of destabilization and re-stabilization, emergence, and controversy, so for me controversy is a subsidiary part of the coproductionist repertoire of where and when we should look. Of course historians would say they look at emergence, but we look at emergence of knowledge cultures and artifactual cultures, and that's a somewhat different thing. We claim that at those moments the kinds of things historians might look at, like the post-colonial identity or something like that, would also include knowledge and information, and those would be implicated in our studies. But we would do such studies with a different eye to the kinds of materials we would look at for instance. So I think these methods prescriptions also translate into how you, as an STS scholar, should go to an archive, what you might think about the limits of the archive, how you might conduct interviews, with whom you would conduct interviews, and so forth. If you're going to be truly symmetrical then it has enormous ramifications for, say, an interview strategy. And then also on the coproductionist theme, I say that we should look at an amalgamation of representations and discourses and institutions and identities, and I think that is a methodological prescription. If you follow Foucault you might look at discourse, or if you follow Latour you might look at representation, or if you are schooled in any number of critical studies you might look at identities. Many people in STS are not looking concurrently at the institutions through which those other things get refracted, so I think it's an STS method to say, "Sorry, no, you've got to look at all these things together." I would like future STS scholars to get that into their bones and have the courage of their convictions and not be deluded by the demonstration or the assertion that other people are doing this too, so what's special in it for you? Specialness I think is better thought of as topographical, not that you're sitting on an island and nobody else is doing what you're doing, but there is a peak you've attained from which you can see some things others can't. In fact, I don't think that knowledge is exciting if you think of yourself as sitting inside your little cave or silo. It's in these kinds of fluid conversations with other ways of seeing that knowledge acquires meaning. So I can point out, and I often do when I'm teaching my students, here is an STS way of asking this question, which is often not the same as when somebody else is asking it. And one can develop that sort of thing, a sensibility about it, without saying, "I am doing something wholly different from what you guys are doing all the time." Nevertheless I would reiterate that certain kinds of things, like the focus on controversies or particular sites, that is methodological and it's much more ours than other people's.

MP Thank you. 


\section{ST(\&)S}

\section{BY MARTYN PICKERSGILL}

One morning in February 2015, I trudged through snow, ice, and eerily empty streets to Sheila Jasanoff's house in Cambridge, MA. Massachusetts was experiencing blizzard after blizzard; flights were being cancelled, Harvard was closed. Nevertheless, Jasanoff was still having a busy day. When I arrived at her home, she was concluding preparation for a Skype conference that would take place shortly after I departed. I kicked the snow of my boots and we sat in her kitchen. We drank hot tea. I thawed out. We chatted.

\section{Building Things}

Jasanoff is known for many things, and one of those is being a builder (even if she sees this as too "intentional" a word for some of the initiatives she has developed). As she reflects, upon arriving at Harvard in 1998 she "had to think about concocting a new STS program because there wasn't one here." Today, Harvard has a vibrant Program in Science, Technology and Society, based in the John F. Kennedy School of Government and directed by Jasanoff. It offers a Secondary Field in STS for doctoral students in the Graduate School of Arts and Sciences, and hosts visiting graduate students and postdoctoral researchers from all over the world.

The building of networks, centers, and disciplines is a key theme running through my interview with Jasanoff. It's striking how much the narrative resonates with tales told by STS scholars themselves when articulating the social dimensions of knowledge-production in other fields. Central to Jasanoff's career-and the research that positions within prestigious universities both enable and depend upon-has been a particular choreography of institutional, financial, epistemic, and collegial support. As the interview shows, the position of choreographer and choreographed are not always "either/or"; in general, they are rather more ambiguously (and sometimes ambivalently) "both/and."

These are the terms used by Jasanoff to discuss her take on the (on-going) question of what "STS" stands for. She describes how "science, technology and society in the US came about because of concerns that were coming out of society"--about war and the environment, for example. It was ostensibly this tradition of STS that first met Jasanoff upon her initial postdoctoral appointment at Cornell. Yet, her interests and engagement with STS as "science and technology studies"--which Jasanoff sees as "to some extent [taking] science and technology as objects of study to look into"- has also long been clear. A movement between "the two STSs" is a hallmark of her scholarship. As she puts it: "I wanted to be at one and the same time science, technology, and society, and science and technology studies." Acting as a nexus point between approaches, Jasanoff's work has facilitated the flourishing of both traditions. 


\section{Entwining Approaches}

Jasanoff's experiences at Cornell exemplify the processes of reciprocal constitution by which careers, scholars, centers, and disciplines come into being. She speaks of the serendipity of arriving into an institution at a time when her own expertise and that of colleagues could be brought together fruitfully to make a research problem "doable" (Fujimura 1987). Over time, through a combination of hard work, intellectual ambition, social relationships, institutional support, and "various ad hoc means," Jasanoff contributed in key ways to building STS at Cornell. In 1991, a one million dollar training grant from the US National Science Foundation helped to elaborate this infrastructure, when the "College of Arts and Sciences voted to convert the program into a department." Building a department of STS, of course, also played an important role in shaping the field per se.

These days it seems that homes for STS within universities nearly always include elements of each of the "two STSs" - whether they and their associated scholarship be formally called "science, technology, and society" (associated more with the US), or "science and technology studies" (generally connected to European approaches). Given her own intellectual orientations, engineering rapprochements between diverse communities in STS has long been important to Jasanoff. When reflecting on her position as an editor of the Handbook of Science and Technology Studies (Jasanoff et al. 1995), she notes: "I was committed from the start to building that bridge between the American and the European" variants of ST(\&)S.

Of course, a range of approaches proliferated within each of these traditions. In the UK, for instance, research in the sociology of scientific knowledge (SSK) was developing in Edinburgh and elsewhere, while the Radical Science Movement in London and beyond was proceeding with urgency (Edge 1995). Bringing these different kinds of perspectives (and their historiographies) together still feels important. For Jasanoff, "STS is the field that reflects most profoundly on what it means for us to be scientific and technological civilizations." This "requires both thinking through where the specialness of science and technology lie" and "what science and technology mean for the rest of the world." Such an intellectual project requires constant movement with and through other disciplinary and discursive spheres, even as positions and styles within STS scholarship are developed and refined.

\section{Disciplining STS}

I remarked above that Jasanoff was having a busy day when we met. Despite the weather, this wasn't a surprise. Productivity, pace, and performance have, increasingly, come to be taken-forgranted (if sometimes resisted) features of academic life (Müller 2014)--and Jasanoff is a particularly busy person. At the same time, she is notable for making significant space for intellectual exchange, perhaps especially with scholars early in their careers. This includes through the international Science and Democracy Network (SDN), as well as the Harvard STS Program. 
The Program itself is a reminder of how "centered" STS tends to be within universities. While social science and humanities departments commonly have one or more STS-inclined scholars on staff, cross-faculty STS programs, institutes, and centers are common. This has ramifications for mentorship, scholarship, and training. Jasanoff argues that in STS, "we have to pay lots more attention to training." Underscoring her own substantial commitment to engaging with (and facilitating dialogue between) younger scholars, she rightly asserts that "we have to train people to be generous and charitable." The ontology of STS is a matter of some enduring contention, but Jasanoff is clear on her position: she "would like to see STS go more in the direction of the disciplines." This includes STS options for students of more traditionally recognized ways of knowing about the world (history, engineering, etcetera), but also undergraduates who want to take STS as a bachelor's degree in its own right.

Some universities (such as Cornell and University College London) take the path Jasanoff recommends. Others (including Edinburgh) tend to provide a limited number of undergraduate course offerings while reserving dedicated STS degrees for postgraduates. How does this hierarchy develop a particular imaginary of what STS is? Conversations about university degree provision are often practical (and economic) in orientation, focusing on nitty-gritty matters of who might teach what, which students might take the course, and, increasingly, how much they would be willing to pay for it. As we know from STS scholarship, it is precisely such concerns that shape the development of fields and the production of knowledge (Capshew 1999).

\section{In the Making}

Jasanoff describes how, for her, "a good field is always a field in the making." Clearly, STS is an (inter)discipline that is constantly being made and remade, as scholars come to interrogate evermore empirical cases and further expand and sharpen conceptual toolkits. Jasanoff's own career and scholarship exemplify the processes of co-production between knowledge and social order that she has so carefully elucidated in other epistemic domains (Jasanoff 2004; 2005). As STS develops, and as the social worlds we work in and with shift and change, it's exciting to ask: what's next?

\section{Author Biography}

Sheila Jasanoff is Pforzheimer Professor of Science and Technology Studies at Harvard's John F. Kennedy School of Government. Her work explores the ways in which science and technology interact with the law, politics, and policy of modern democracies, paying particular attention to the nature of public reason. Jasanoff's scholarship has emphasized the "co-production" of science and social order, and introduced terms such as "sociotechnical imaginaries" and "bioconstitutionalism" into the conceptual vocabularies of the social sciences and humanities. With degrees in mathematics, linguistics and law, Jasanoff came to STS through cross-national research comparing the regulation of toxic substances in the US, the UK and Germany. This work demonstrated how political culture shapes both the production and 
deployment of evidence, and the recognition and negotiation of expertise in policymaking. Her subsequent research has retained this focus on international comparison, including work on Bhopal, the IPCC, and the global environmental movement. Before taking up her current position she was founding chair of the STS Department at Cornell University. She has held many important appointments, such as serving as President of the Society for Social Studies of Science, and regularly works with and writes for non-STS audiences, such as scientists and wider publics, drawing on insights of STS to analyze—and shape—contested issues in science policy.

\section{Author Biography}

Martyn Pickersgill is Wellcome Trust Reader in Social Studies of Biomedicine in Edinburgh Medical School. His research examines the international circulation of scientific and medical knowledge, and its instantiation within healthcare, law and policy, and everyday life. Pickersgill's work has focused in particular on the social and historical dimensions of neuroscience, psychiatry, and psychology. It has cast new light on (for instance) sociotechnical innovation within mental health praxis, the (co)production of normativities in clinical and laboratory work, and the configuration of subjectivities in relation to novel epistemologies. Pickersgill has held grants and fellowships from a range of bodies, including the Wellcome Trust, Leverhulme Trust, and British Academy. In 2014, he co-founded the Centre for Science, Knowledge and Policy (SKAPE), and remains an Associate Director; Pickersgill is currently codeveloping a new Centre for Biomedicine, Self, and Society (seeded with a $£ 1$ million award from the Wellcome Trust). He is committed to diverse forms of engagement with a range of sectors and actors, and has participated in dialogical events in pubs, cinemas, hospitals, and beyond; increasingly, Pickersgill employs public engagement as a research method in itself. In 2015, the Royal Society of Edinburgh awarded him its Henry Duncan Medal.

\section{References}

Capshew, J. H. 1999. Psychologists on the March: Science, Practice, and Professional Identity in America, 1929-1969. Cambridge: Cambridge University Press.

Edge, D. 1995. "Reinventing the wheel." In Handbook of Science and Technology Studies edited by S. Jasanoff, G. E. Markle, J. C. Petersen, and T. Pinch. 3-24. London: Sage.

Fujimura, J. 1987. "Constructing 'do-able' problems in cancer research: Articulating alignment." Social Studies of Science 17(2):257-293.

Jasanoff, S. ed. 2004. States of Knowledge: The Co-Production of Science and Social Order. London: Routledge.

Jasanoff, S. 2005. Designs on Nature: Science and Democracy in Europe and the United States. Princeton, NJ: Princeton University Press.

Jasanoff, S., G. E. Markle, J. C. Petersen and T. Pinch. eds. 1995. Handbook of Science and Technology Studies. London: Sage. 
Müller, R. 2014. "Postdoctoral life scientists and supervision work in the contemporary university: A case study of changes in the cultural norms of science." Minerva 52(3):329349 . 